\title{
PET/CT significance for planning radiotherapy of head and neck cancer
}

\author{
I. KOLAROVA ${ }^{1,6, *}$, J. VANASEK ${ }^{1,6}$, V. KANDRNAL ${ }^{7}$, K. ODRAZKA $^{1}$, L. DUSEK ${ }^{7}$, V. CHROBOK ${ }^{3}$, O. BELOHLAVEK $^{2}$, M. DOLEZEL $^{1}$, L. PETRUZELKA $^{4}$, \\ R. MICHALEK 5,6 , J. JARKOVSKY ${ }^{7}$ \\ ${ }^{1}$ Department of Radiation and Clinical Oncology, Multiscan Ltd., Pardubice; ${ }^{2}$ Department of Nuclear Medicine, PET Centre, Hospital Na Homolce, \\ Prague; ${ }^{3}$ Department of Otorhinolaryngology and Head and Neck Surgery, University Hospital and Faculty of Medicine at the Charles University, \\ Hradec Kralove; ${ }^{4}$ Department of Oncology, University Hospital and $11^{\text {st }}$ Faculty of Medicine at the Charles University, Prague; ${ }^{5}$ Otorhinolaryngology \\ and Head and Neck Surgery Clinic, Regional Hospital Pardubice; ${ }^{6}$ Faculty of Health Studies, University of Pardubice; ${ }^{7}$ Institute of Biostatistics \\ and Analyses, Faculty of Medicine and Faculty of Science, Masaryk University, Brno
}

*Correspondence: iveta.kolarova@nemocnice-pardubice.cz

Received February 20, 2012 / Accepted March 29, 2012

\begin{abstract}
The combination of positron emission tomography and computed tomography (PET/CT) offers metabolic mapping in addition to anatomic information of the primary lesion, nodal and distant metastases in patients with head and neck tumors, and may be therefore beneficial for radiotherapy planning. The aim of our study was to evaluate benefits of combined PET and CT imaging for staging and target volume delineation in this group of patients.

Fifty three patients ( 40 men and 13 women) with confirmed advanced, inoperable or non-radically operated head and neck cancer were assessed based on the results of PET/CT as well as standard diagnostic examinations. All patients were subsequently treated with intensity modulated radiotherapy (IMRT) with simultaneous integrated boost (SIB) of 6 MV X-rays.

There was an agreement between the standard examinations results and results of PET/CT in 30 cases. In 23 cases there was disagreement either in tumor size, nodal involvement or presence of distant metastases. Results of the tumor size assessment differed significantly in 5 cases. There was no agreement found in nodal involvement in 10 cases. The cancer confirmed by standard examination was not found by PET/CT in 2 cases; 3 PET/CT positive findings were not confirmed by standard examinations. In 3 patients PET-CT revealed new distant metastatic disease. Based on PET/CT assessment we changed treatment strategy and applied potentially curative dose of radiotherapy to previously undiscovered regions in 9 patients. We decided to change the treatment intent in 3 cases and only palliative treatment was applied. Based on our experience and the literature review, PET/CT may be considerable contribution to the standard diagnostic procedures in approximately one third of cases.
\end{abstract}

Key words: PET-CT, radiotherapy treatment planning, head and neck cancer, IMRT

Radiotherapy is next to surgery one of the most effective modalities for treating head and neck tumors. This is due to the routine application of modern techniques, such as IMRT. Selection of different treatment modalities (surgery, radiotherapy, systemic chemotherapy and/or biological therapy) depends on the tumor localization, size, histological type of tumor, presence of nodal involvement and distant metastases, patient's performance status, co-morbidities and of course on patient's preference of the treatment modality $[1,2]$.

Introduction of intensity-modulated radiation therapy made possible to deliver a high dose of radiation to the target volume, while relatively saving surrounding tissues. A potential negative impact of radiation therapy on surrounding critical structures unaffected by cancer is particularly important in the head and neck region. IMRT may deliver increased dose of radiation in the target volume and thus improve loco-regional control of the disease, while reducing common side effects, particularly xerostomia $[3,4]$. However, compared with conventional radiation techniques, it requires increased precision of the target volume delineation in order to reduce the risk of the relapse due to potential miss of tumor involvement. The basic imaging technique for the radiotherapy contouring and planning is computed tomography (CT), which is the only method that allows the calculation of the dose distribution taking into account tissue inhomogeneity. Unfortunately, CT is often not sufficient for precise tumor definition. Enlarged 
inflammatory and/or reactive lymph nodes are often mistaken for malignity with lymph node involvement and small primary tumors may be missed or assessed insufficiently.

In addition to standard examinations, 18 FDG (2-[18F]fluoro2-deoxy-D-glucose) positron emission tomography (PET) can be used for disease staging. PET offers new diagnostic possibilities as it supplements the morphological imaging with a functional view. Numerous studies have shown that PET is superior to CT in identifying primary lesions and metastases in patients with head-and-neck cancer [5,6]. A hybrid PETCT can provide additional information by combining PET and CT images and create results with increased geometric accuracy. High sensitivity and specificity of PET in oncology have been reported: sensitivity between $84 \%$ and $87 \%$ (18 402 patients examined) and specificity between $88 \%$ and $93 \%$ (14 264 patients examined) [7]. Some authors report even higher sensitivity and specificity of PET examination for assessing head and neck tumors and/or nodal involvement in respective areas $[8,9]$.

PET is more accurate then computed tomography or magnetic resonance imaging and can be useful for identifying the primary tumor in patients presenting with metastases to cervical nodes. In addition, PET can identify unsuspected distant metastases and define regional disease in nodal regions. PET can detect additional tumors, especially in the lung and aerodigestive tract. The overall incidence of coincidental primary tumors is near $8 \%$. PET is valuable for detecting recurrent disease because $\mathrm{CT}$ and MRI are limited in the postoperative neck. [10].

Data from the literature suggests that treatment planning based on PET-CT may considerably differ from the planning based solely on CT imaging $[11,12]$.

Estimated $30 \%$ to $40 \%$ of radiation plans were modified due to the use of PET examinations in the planning process. In addition, the radiation dose increased by $10 \%$ to $20 \%$ can be specifically applied into PET-positive regions [13].

Main aim of our study was to evaluate benefits of combined PET and CT imaging for assessment of primary tumor volume and disease staging based on TNM classification in patients with head and neck tumors.

\section{Patients and methods}

From July 2006 to March 2008, a total of 53 patients (40 men and 13 women) with advanced inoperable or nonradically operated head and neck cancers were treated at our department. The median age was 56 years (ranging from 20 to 75 years). The basic clinical characteristics are summarized in tables 1 and 2. The histopathology examination confirmed squamous cell carcinoma $(n=42)$, undiferentiated carcinoma $(\mathrm{n}=2)$, adenoid cystic carcinoma $(\mathrm{n}=2)$, lymphoepithelioma $(\mathrm{n}=5)$, and mucoepidermoid carcinoma $(\mathrm{n}=2)$. In 5 cases primary tumors were localized in nasal and paranasal cavity, 15 tumors were in nasopharynx or larynx, 12 primary tumors were localized in oral cavity, 3 were found in salivary glands, 15 were in oropharynx or hypopharynx and in 3 cases we found metastases in neck lymph nodes with unknown location of primary tumor (table 1).

PET-CT. A quality assurance and patient management protocol of our institution was applied in all cases together with standard PET-CT procedures. All patients provided a written consent to treatment and data collection. All processes were in compliance with ethical as well as legal requirement for non-interventional anonymous data collection in the Czech Republic. Standard pre-treatment staging included a contrast-enhanced CT scan of the head and neck, direct otorhinolaringologic endoscopic examination, ultrasound of the neck and chest X-ray. Following standard examinations, all fifty-three patients were examined in the treatment position on a hybrid PET-CT scanner Siemens Biograph duo LSO PET/CT at the PET Centre, Hospital Na Homolce Praha. Patients were immobilized with thermoplastic head and neck masks. Images were transferred to the Varian Eclipse planning system with the Helios module for inverse planning. The interpretation of PET-CT examination by a qualified radiologist was a basis for identification of involved regions. All scans were assessed by one radiologist. Target volumes and critical organs were contoured and IMRT plans were generated based on the fused images. Results were compared with the plans based on the standard diagnostic examinations.

Abnormal areas of primary tumor and nodal regions showing 18FDG uptake were contoured on PET/CT, assessing the gross tumor volume (GTV). CTVs (clinical target volumes) and PTVs (planning target volumes) were estimated based on the guidelines according to the involvement localization and disease stage [14]. If there was a disagreement between standard examinations and PET/CT, the stage was re-assessed by both radiographer as well as treating physician.

Table 1. Primary tumor

\begin{tabular}{lc}
\hline Involved site & Number of patients \\
\hline Nasal and paranasal cavity & 5 \\
Nasopharynx & 8 \\
Larynx & 7 \\
Oral cavity & 12 \\
Salivary glands & 3 \\
Hypopharynx & 5 \\
Oropharynx & 10 \\
Metastases in neck nodes - unknown primary & 3 \\
\hline Total & 53 \\
\hline Histopathology & Number of patients \\
\hline Squamous cell carcinoma & 42 \\
Undiferentiated carcinoma & 2 \\
Adenoid cystic carcinoma & 2 \\
Lymphoepithelioma & 5 \\
Mucoepidermoid carcinoma & 2 \\
\hline Total & 53 \\
\hline
\end{tabular}


Table 2. Tumor stage based on CT

\begin{tabular}{ll}
\hline T-stage & \\
\hline T1 & 2 \\
T1b & 1 \\
T2 & 8 \\
T2a & 1 \\
T2b & 1 \\
rT3 & 1 \\
T3 & 10 \\
T4 & 11 \\
T4a & 10 \\
T4b & 3 \\
O(X) & 5 \\
\hline N-stage & \\
\hline N0 & 14 \\
N1 & 5 \\
N2 & 10 \\
N2b & 8 \\
N2c & 12 \\
N3 & 4 \\
\hline
\end{tabular}

Subsequent treatment. Following re-assessment, simultaneous integrated boost techniques were performed using either 2.2 Gy or 2.11 Gy per fraction to a total dose of 66-70 Gy. Intermediate and low doses of 54-60 Gy were individually defined to regions considered at high risk for microscopic disease.

The radiation dose was prescribed according to the International Commission on Radiation Units and Measurements (ICRU Report) $[15,16]$.

Table 3. Changes in tumor stage based on PET-CT examination

\begin{tabular}{lccc}
\hline $\begin{array}{l}\text { TNM/tumor } \\
\text { structure }\end{array}$ & $\begin{array}{c}\text { Target volume } \\
\text { change }\end{array}$ & $\begin{array}{c}\text { Number of } \\
\text { cases }\end{array}$ & $\begin{array}{c}\text { Total number of } \\
\text { cases }\end{array}$ \\
\hline No change & No change & 30 & $30(56,6 \%)$ \\
\hline \multirow{2}{*}{ N higher } & $\mathrm{N} 0 \rightarrow \mathrm{N} 1$ & 2 & $5(9,4 \%)$ \\
& $\mathrm{N} 1 \rightarrow \mathrm{N} 2$ & 1 & \\
& $\mathrm{~N} 2 \mathrm{a} \rightarrow \mathrm{N} 2 \mathrm{~b}$ & 1 & \\
$\mathrm{~N} 2 \mathrm{~b} \rightarrow \mathrm{N} 2 \mathrm{c}$ & 1 & $5(9,4 \%)$ \\
\hline \multirow{3}{*}{ N lower } & $\mathrm{N} 1 \rightarrow \mathrm{N} 0$ & 3 & \\
& $\mathrm{~N} 2 \mathrm{c} \rightarrow \mathrm{N} 1$ & 1 & $4(7,5 \%)$ \\
& $\mathrm{N} 2 \rightarrow \mathrm{N} 0$ & 1 & \\
T higher & $\mathrm{TX} \rightarrow \mathrm{T} 1$ & 1 & $1(1,9 \%)$ \\
\hline T lower & $\mathrm{TX} \rightarrow \mathrm{T} 2$ & 1 & $3(5,7 \%)$ \\
\hline M higher & $\mathrm{TX} \rightarrow \mathrm{T} 4 \mathrm{c}$ & 1 & $3(5,7 \%)$ \\
\hline False positive & $\mathrm{T} 3 \rightarrow \mathrm{T} 4$ & 1 & $2(3,8 \%)$ \\
\hline False negative & $\mathrm{T} 4 \mathrm{a} \rightarrow \mathrm{T} 3$ & 1 & $53(100 \%)$ \\
\hline Sum & $\mathrm{M} 0 \rightarrow \mathrm{M} 1$ & 3 &
\end{tabular}

\section{Results}

Agreement between conventional staging (a contrast-enhanced CT scan of the head and neck, direct otorhinolaringologic endoscopic examination, ultrasound of the neck and chest X-ray) and the staging based on PET/CT examination was found in 30 patients (56.6\%). Disagreement in remaining 23 cases was either in confirmation of the primary tumor site, its size, nodal involvement and/or presence of distant metastases (table3).

Based on PET/CT examination the tumor was significantly larger in 1 case and smaller in one another. Three new primary tumors not identified by conventional imaging techniques were confirmed by PET/CT.

The PET/CT examination revealed an extensive tumor destructing a scull base in one case, relatively small primary tumor at the base of the tongue and primary tumor in nasopharynx in the second and third case, respectively. These findings were subsequently verified by histology.

In 5 cases PET/CT confirmed higher nodal involvement; in 5 cases fewer nodal areas were affected. As a result of conventional staging enhancement by PET/CT, new distant metastases were confirmed in 3 cases.

PET/CT did not confirm one case of residual disease after surgery, and one case of the primary tumor identified by standard diagnostic methods. We regard them as falsely negative cases.

We were also unable to confirm two PET/CT positive findings in terms of a newly diagnosed primary tumor and one case of lung metastases either with CT or other conventional methods. We regard these findings as falsely positive.

The re-assessment of the tumor staging and the size of the primary tumor led to subsequent adjustment of the gross target volume in 15 cases (28.3\%). Based on PET/CT assessment we changed treatment techniques. High dose volume was enlarged based on PET/CT assessment and potentially curative dose of radiotherapy was applied to involved region in 9 patients. In 3 cases the palliative treatment was recommended instead of curative approach.

\section{Discussion}

In our group of 53 patients, agreement between conventional diagnostic method findings and the PET/CT examination was found in 30 cases $(56.6 \%)$. The primary tumor size was different in 9 cases. However, we regarded the results in 2 cases as false positivity and in 2 cases as false negativity. The nodal involvement was more extensive in 5 cases, less extensive in other 5 cases. New metastases were found by PET/CT in 3 cases. One case of distant lung metastasis identified by PET/CT was not confirmed by conventional methods including histology.

In 2010 Misono et al. observed 65 patients with head and neck tumors and compared PET findings with conventional diagnostic methods. Agreement was found in $63 \%$ of cases. Disease was found to be more extensive in $20 \%$ patients, $2 \%$ of 
cases were regarded as falsely positive. Staging was decreased based on the PET examination in 6\% [17].

Koshy et al. compared TNM classification of 36 patients, based on the conventional methods and PET/CT. They reported staging change in $36 \%$ of patients. However, this led to the target volume change only in $14 \%$ of patients [11].

$\mathrm{Ha}$ et al. tried to evaluate possible role of PET and PET/CT examination on treatment planning in patients with both small and advanced head and neck tumors. In their study of a group of 36 patients, the treatment plan was changed in 11 patients (31\%); 6 patients were confirmed to have more extensive disease than initially expected based on the conventional methods finding. PET/CT assessed correctly extent of the primary tumor in all 18 patients who received surgical treatment. However, the extent of nodal involvement was shown correctly by PET/CT only in nine of them. Two patients did not have the lymphatic nodes removed for histopathology examination [6].

Deantonio and her colleagues observed 22 patients with head and neck tumors indicated for primary curative radiotherapy. They compared results of conventional diagnostic methods and PET/CT and reported a change in TNM classification in 5 cases. Overall gross tumor volume was higher by $6 \mathrm{~cm}^{3}$ based on PET/CT, in comparison with CT based GTV [12].

It seems unlikely that a PET/CT assessment will always lead to increase of gross tumor volume. Some studies suggest that FDG-PET may lead to a decrease of the target volume and thus spare critical surrounding tissues. Several authors reported a significant reduction of targeted volumes in some of their patients [18-21].

It is clear that PET/CT provides us with additional information regarding size of the primary tumor and its relation to surrounding tissues. In considerable number of patients this examination reveals nodal involvement not identified by conventional methods [18,22].

Reduced target volumes may spare critical surrounding tissues and reduce adverse treatment reactions [22]. However, they may also lead to suboptimal disease control. A recently published case study described loco-regional recurrence of a parotid salivary gland primary tumor in 3 patients treated with IMRT [23]. In two cases the recurrence occurred in periparotic lymph nodes which appeared to be unaffected by the disease based on PET/CT examination. Whether it was due to a necrosis of affected lymph nodes or a limitation of the diagnostic technique itself is difficult to say. However, significant discrepancy between findings of conventional diagnostic methods and PET/CT should be always regarded as very suspicious and all such cases should be re-assessed using all available diagnostic methods [24].

It is estimated that primary location is not found in approximately $1-2 \%$ newly diagnosed head and neck metastatic tumors and a PET/CT examination may considerably contribute to their identification [25-27]. In our case, PET/CT located all 3 cases of primary tumors unidentified by conventional diagnostic methods.
PET/CT also plays an important role in identification of new metastases and it is recommended by numerous authors for ruling out distant metastases in uncertain cases. The distant metastases unidentified by conventional methods were found in 3 (5.7\%) of our patients.

A combined PET and CT examination may be beneficial in follow-up setting for identification of early recurrences following IMRT [27]. Whether it will become a part of a routine assessment is to be seen.

A PET examination brings additional information about the tumor, such as a presence and localization of hypoxic areas and/or areas of increased proliferation. This can help us to target predominantly specific hypermetabolic areas as well as potentially radio-resistant hypoxic tumor areas suitable for IMRT treatment $[28,29]$.

\section{Conclusion}

There is still no agreement on the role of PET/CT for radiotherapy planning in head and neck tumors. Evaluation of target volume remains the most important part of radiotherapy planning and a clinical examination together with $\mathrm{CT}$ remains the optimal standard. PET/CT gives us additional information about tumor size and structure which may, in some cases, help us to plan radiotherapy more precisely. Even PET/CT is unable to identify microscopic tumors and in many cases does not change the extent of prophylactic radiation. PET/CT allows us more precise evaluation of tumor size and definition; however, to what extent this improves the treatment outcomes and patients' quality of life is unclear and will require further research.

\section{References}

[1] POSNER MR Integrating systemic agents into multimodality treatment of locally advanced head and neck cancer. Ann Oncol 2010; 21: 246-251.

[2] QUON A, FISCHBEIN N J, MCDOUGALL IR, LE QT, LOO BW et al. Clinical role of $18 \mathrm{~F}-\mathrm{FDG}$ PET/CT in the management of squamous cell carcinoma of the head and neck and thyroid carcinoma. J Nucl Med 2007; 48: 58S-67S.

[3] GRAFF P, LAPEYRE M, DESANDES E, ORTHOLAN C, BENSADOUN RJ et al. Impact of intensity-modulated radiotherapy on health-related quality of life for head and neck cancer patients: Matched-pair comparison with conventional radiotherapy. Int J Radiat Oncol Biol Phys 2007; 67: 1309-1317. http://dx.doi.org/10.1016/j.ijrobp.2006.11.012

[4] LEE N, PURI D R, BLANCO AL, CHAO KSC Intensity-modulated radiation therapy in head and neck cancers: An update. Head Neck 2007; 29: 387-400. http://dx.doi.org/10.1002/ hed.20332

[5] GORDIN A, DAITZCHMAN M, DOWECK I, YEFREMOV N, GOLZ A et al. Fluorodeoxyglucose-positron emission tomography/computed tomography imaging in patients with carcinoma of the larynx: diagnostic accuracy and impact on 
clinical management. Laryngoscope 2006; 116: 273-278. http://dx.doi.org/10.1097/01.mlg.0000197930.93582.32

[6] HA PK, HDEIB A, GOLDENBERG D, JACENE H,PATEL P et al. The role of positron emission tomography and computed tomography fusion in the management of early-stage and advanced-stage primary head and neck squamous cell carcinoma. Arch Otolaryngol Head Neck Surg 2006; 132: 12-16. http://dx.doi.org/10.1001/archotol.132.1.12

[7] GAMBHIR SS, CZERNIN J, SCHWIMMER J, SILVERMAN DHS, COLEMAN RE et al. A tabulated summary of the FDG PET literature. J Nucl Med 2001; 42: 1S-93S.

[8] ROTHSCHILD S, STUDER G, SEIFERT B, HUGUENIN P, GLANZMANN C et al. PET/CT staging followed by intensitymodulated radiotherapy (IMRT) improves treatment outcome of locally advanced pharyngeal carcinoma: A matchedpair comparison. Radiat Oncol 2007; 2: 22. http://dx.doi. org/10.1186/1748-717X-2-22

[9] SCARFONE C, LAVELY WC, CMELAK AJ, DELBEKE D, MARTIN WH et al. Prospective feasibility trial of radiotherapy target definition for head and neck cancer using 3-dimensional PET and CT imaging. J Nucl Med 2004; 45: 543-552.

[10] LIN EC, ALAVI A. PET and PET/CT: A clinical guide. New York: Thieme Medical Publishers, Inc., 2005: 95-99. ISBN 3 131417315.

[11] KOSHY M, PAULINO AC, HOWELL R, SCHUSTER D, HALKAR R et al. F-18 FDG PET-CT fusion in radiotherapy treatment planning for head and neck cancer. Head Neck 2005; 27: 494-502. http://dx.doi.org/10.1002/hed.20179

[12] DEANTONIO L, BELDI D, GAMBARO G, LOI G, BRAMBILLA $M$ et al. FDG-PET/CT imaging for staging and radiotherapy treatment planning of head and neck carcinoma. Radiat Oncol; 2008: 29. http://dx.doi.org/10.1186/1748-717X$\underline{3-29}$

[13] DIZENDORF EV, BAUMERT BG, VON SCHULTHESS GK, LUTOLF UM, STEINERT HC Impact of whole-body 18FFGD PET on staging and managing patients for radiation therapy. J Nucl Med 2003; 44: 24-29.

[14] GREGOIRE V, EISBRUCH A, HAMOIR M, LEVENDAG P Proposal for the delineation of the nodal CTV in the nodepositive and the post-operative neck. Radiother Oncol 2006; 79: 15-20. http://dx.doi.org/10.1016/j.radonc.2006.03.009

[15] ICRU. ICRU Report, vol. 50. Bethesda. International Commission on Radiation Units and Measurements. 1993. Prescribing, recording, and reporting photon beam therapy.

[16] ICRU. ICRU Report, vol. 62. Bethesda. International Commission on Radiation Units and Measurements. 1999.

[17] MISONO S, RUE T, RAJENDRAN J, DAVIS GE Effects of upstaging from PET scan on survival in head and neck squamous cell carcinoma. Head Neck 2010; 32: 1283-1287. http://dx.doi.org/10.1002/hed.21333

[18] WANG D, SCHULTZ CJ, JURSINIC PA, BIALKOWSKI $\mathrm{M}, \mathrm{ZHU}$ XR et al. Initial experience of FDG-PET/CT guided IMRT of head-and-neck carcinoma. Int J Radiat Oncol Biol Phys 2006; 65: 143-151. http://dx.doi.org/10.1016/ j.ijrobp.2005.11.048

[19] CIERNIK IF, DIZENDORF E, BAUMERT BG, REINER $\mathrm{B}, \mathrm{BURGER} \mathrm{C}$ et al. Radiation treatment planning with an integrated positron emission and computer tomography (PET/ CT): a feasibility study. Int J Radiat Oncol Biol Phys 2003; 57: 853-863. http://dx.doi.org/10.1016/S0360-3016(03)00346-8

[20] PAULINO AC, KOSHY M, HOWELL R, SCHUSTER D, DAVIS LW Comparison of CT and FDG-PET-defined gross tumor volume in intensity-modulated radiotherapy for head-and-neck cancer. Int J Radiat Oncol Biol Phys 2005; 61: 1385-1392. http://dx.doi.org/10.1016/j.ijrobp.2004.08.037

[21] DAISNE JF, DUPREZT, WEYNAND B, LONNEUX M, HAMOIR $M$ et al. Tumor volume in pharyngolaryngeal squamous cell carcinoma: comparison at CT, MR imaging, and FDG PET and validation with surgical specimen. Radiology 2004; 233: 93-100. http://dx.doi.org/10.1148/radiol.2331030660

[22] NISHIOKA T, SHIGA T, SHIRATO H, TSUKAMOTO E, TSUCHIYA K et al. Image fusion between 18FDG-PET and MRI/CT for radiotherapy planning of oropharyngeal and nasopharyngeal carcinomas. Int Radiat Oncol Biol Phys 2002; 53: 1051-1057. http://dx.doi.org/10.1016/S0360-3016(02)02854$\underline{7}$

[23] CANNON DM, LEE NY Recurrence in region of spared parotid gland after definitive intensity-modulated radiotherapy for head and neck cancer. Int J Radiat Oncol Biol Phys 2008; 70: 660-665. http://dx.doi.org/10.1016/j.ijrobp.2007.09.018

[24] FORD EC, HERMAN J, YORKE E, WAHL RL 18F-FDG PET/ CT for image-guided and intensity-modulated radiotherapy. J Nucl Med 2009; 50: 1655-1665. http://dx.doi.org/10.2967/ jnumed.108.055780

[25] BELDI D, JERECZEK-FOSSA BA, D'ONOFRIO A, GAMBARO G, FIORE MR et al. Role of radiotherapy in the treatment of cervical lymph node metastases from unknown primary site: retrospective analysis of 113 patients. Int J Radiat Oncol Biol Phys 2007; 69: 1051-1058. http://dx.doi. org/10.1016/j.ijrobp.2007.04.039

[26] ZIMMER L, BRANSTETTER B, NAYAK J, JOHNSON JT Current use of 18-Fluoroedoxyglucose positron emission tomography and combined positron emission tomography and computed tomography in squamous cell carcinoma of the head and neck. Laryngoscope 2005; 115: 2029-2034. http://dx.doi.org/10.1097/01.MLG.0000181495.94611.A6

[27] SCHECHTER NR, GILLENWATER AM, BYERS RM, GARDEN AS, MORRISON WH et al. Can positron emission tomography improve the quality of care for head-and-neck cancer patients? Int J Radiat Oncol Biol Phys 2001; 51: 4-9. http://dx.doi.org/10.1016/S0360-3016(01)01642-X

[28] DIRIX P, VANDECAVEYE V, DEKEYZER F, STROOBANTS $S$, HERMANS R et al. Dose painting in radiotherapy for head and neck squamous cell carcinoma: Value of repeated functional imaging with 18F-FDG PET, 18F-fluoromisonidazole PET, diffusion-weighted MRI, and dynamic contrast-enhanced MRI. J Nucl Med 2009; 50: 1020-1027. http://dx.doi. org/10.2967/jnumed.109.062638

[29] LEE NI, MECHALOKOS JG, NEHMEH S, LIN Z, SQUIRE $\mathrm{OD}$ et al. Fluorine-18 labeled fluoromisonidazole positron emission and computed tomography-guided intensity-modulated radiotherapy for head and neck cancer: a feasibility study. Int J Radiat Oncol Biol Phys 2008; 70: 2-13. http://dx.doi. org/10.1016/j.ijrobp.2007.06.039 